\title{
Microstructure and Thermomechanical Properties of Shape Memory Alloys $\mathrm{TI}_{50}-\mathrm{NI}_{50}$ Elaborated by Arc Melting and by Powder Metallurgy
}

\author{
P. Olier***, J.C. Brachet** and G. Guenin*** \\ * INSTN/SEPEM, C.E. Saclay, 91191 Gif-sur-Yvette cedex, France \\ ** CEREM/DECM/SRMA, C.E. Saclay, 91191 Gif-sur-Yvette cedex, France \\ *** GEMPPM, INSA de Lyon, 20 avenue Albert Einstein, 69621 Villeurbanne cedex, France
}

\begin{abstract}
This study was focussed on the elaboration and transformation of $\mathrm{Ti}_{50} \mathrm{Ni}_{50}$ shape memory alloys in relation to structural and thermomechanical properties. An original method for producing TiNi alloys by powder metallurgy (PM), through combustion synthesis, was developed. After hot extrusion, intermetallic rods without porosity were obtained. Microstructural and thermomechanical properties of products obtained by this method were systematically compared to those of some alloys elaborated by the more conventionnal method of arc melting (AM). For comparison, cast products were hot rolled at different temperatures; for all the transformation conditions used, the grain size remained coarser and more heterogeneous compared to PM products. Investigation of the thermomechanical behaviour was conducted by tensile and flexion tests. It was found that :

- The ultimate tensile strength and the recovery stress were in the same range for PM and AM products but the ductility of PM products was enhanced.

- The better one way shape memory recovery is obtained for a PM product with an oxygen content of about $1200 \mathrm{ppm}$. Also, too low content of oxygen $(<600 \mathrm{ppm})$ seems to decrease the stress and strain recovery during thermomechanical cycling.
\end{abstract}

\section{INTRODUCTION}

Up to now, the relation between the thermomechanical properties of TiNi shape memory alloys and the processing parameters (elaboration and working) have not been systematically studied. Conventionally, TiNi shape memory alloys are produced by arc melting. For this technique, the liquid alloy needs to be melted several times to prevent microstructural segregation, and subsequent mechanical working (hot or cold rolling, swaging, etc...) is required to achieve a homogeneous product and to reduce the grain size. In contrast, powder metallurgy through combustion synthesis, which is a newly developed technique, can be used to successfully produce NiTi alloys with improved mechanical properties.

In this study, the influence of these two modes of elaboration on the characteristics of the final product (microstructure and thermomechanical properties) were systematically investigated. It must be noted that powder metallurgy associated with a conventionnal sintering (by diffusion at high temperature, $900^{\circ} \mathrm{C}$ ) was also investigated. With respect to the granulometry of the powder used, this technique did not allow to obtain good products because of the occurence of porosity due to the Kirkendall effect [1].

A part of this work was also devoted to obtain a better understanding of the influence of oxygen on properties, as this is a major impurity [2] [3]. 


\section{FABRICATION ROUTE AND CHEMICAL COMPOSITION OF THE ALLOYS}

The equiatomic NiTi alloys were obtained by two differents methods :

- Arc melting : the conventional tungsten melting technique was employed. Nickel (purity, 99,9\%) associated with titanium 1 (purity $99,7 \%$ ) or titanium 2 (purity, 99,9\%) was remelted at least four times in an argon atmosphere to obtain the final ingot. This one was homogenized at $900^{\circ} \mathrm{C}$ for 1 hour and quenched in water. Hot rolling was then performed ( $75 \%$ thickness reduction) to reduce the grain size and to enhance the thermomechanical properties. Finally, a heat treatment at $900^{\circ} \mathrm{C}$ for $24 \mathrm{~h}$ was used to homogenize the hot-rolled plates.

-Powder metallurgy through combustion synthesis : This less conventional fabrication route is based on the use of the exothermic reaction between pure $\mathrm{Ti}$ and $\mathrm{Ni}$ powders to synthesize the equiatomic TiNi phase (thermal explosion mode) [4]. This method associated with a hot extrusion allowed a rapid synthesis of a final product (rod) without porosity. Resulting samples were homogenized at $900^{\circ} \mathrm{C}$ for $72 \mathrm{~h}$.

The main constituents of the different TiNi alloys elaborated are presented on table 1.

Table 1/Chemical content of the alloys studied:

\begin{tabular}{|c|c|c|c|c|c|c|}
\hline Sample & Elaboration & Transformation & wt\%Ti & wt\%Ni & wt\%O & wt\%Fe \\
\hline C1 & Arc melting & Hot rolling $\left(600^{\circ} \mathrm{C}\right)$ & $44.8 \pm 0.2$ & $54.6 \pm 0.2$ & $0.063 \pm 0.002$ & $0.02 \pm 0.01$ \\
\hline C2 & Arc melting & Hot rolling $\left(850^{\circ} \mathrm{C}\right)$ & $44.9 \pm 0.2$ & $55.0 \pm 0.2$ & $0.062 \pm 0.002$ & $0.02 \pm 0.01$ \\
\hline C3 & Arc melting & Hot rolling $\left(850^{\circ} \mathrm{C}\right)$ & $45.0 \pm 0.2$ & $54.9 \pm 0.2$ & $\mathbf{0 . 0 1 6} \pm \mathbf{0 . 0 0 1}$ & $0.01 \pm 0.01$ \\
\hline P1 & Powder met. & Extrusion $\left(900^{\circ} \mathrm{C}\right)$ & $44.6 \pm 0.2$ & $54.6 \pm 0.2$ & $0.060 \pm 0.002$ & $0.11 \pm 0.02$ \\
\hline P2 & Powder met. & Extrusion $\left(900^{\circ} \mathrm{C}\right)$ & $44.7 \pm 0.2$ & $55.0 \pm 0.2$ & $\mathbf{0 . 1 2} \pm \mathbf{0 . 0 1}$ & $0.12 \pm 0.02$ \\
\hline
\end{tabular}

\section{RESULTS AND DISCUSSION}

\subsection{Microstructure}

Microstructures after electrolytic polishing are presented in Fig.1. Precipitation, which is preferentially orientated in the direction of hot working, has been observed for both types of alloys. The micrograph sequence show that the fraction of precipitates increases with increasing the oxygen concentration. This precipitation could be associated to a dispersion of oxides ( $\mathrm{Ti}_{2} \mathrm{Ni}$ associated with oxygen). An investigation by $\mathrm{X}$-ray analysis (oxygen detection may be allowed by working with a thin aluminium window on the scanning electron microscope) gave a possible stiochiometry of $\mathrm{Ti}_{4} \mathrm{Ni}_{2} \mathrm{O}$ for the precipitates in accordance with literature [2] [3] [5] [6].

The grain size has been evaluated using polarized light [7] (Fig.2). The smallest grain size is obtained for PM products $(\sim 20 \mu \mathrm{m})$ while in cast products the grain refinement is less pronounced, especially if the hot rolling is performed at $850^{\circ} \mathrm{C}$, where some recrystallisation occurs. Moreover, the heterogeneous grain size distribution is still present after homogeneisation of the hot-rolled alloys.

\subsection{Transformation temperatures}

The typical phase transformation temperatures of the different alloys studied have been measured by DSC (heating/cooling rate $=5^{\circ} \mathrm{C} / \mathrm{mn}$ ) and are presented in Table 2 .

Table 2 / Typical phase transformation temperatures measured by DSC :

\begin{tabular}{|c|c|c|c|c|c|}
\hline Sample & $\mathrm{M}(90 \%)$ & $\mathrm{M}(10 \%)$ & $\mathrm{A}(10 \%)$ & $\mathrm{A}(90 \%)$ & Hysteresis \\
\hline $\mathrm{C} 1$ & 36 & 50 & 66 & 83 & 25 \\
\hline $\mathrm{C} 2$ & 25 & 45 & 63 & 80 & 32 \\
\hline $\mathrm{C} 3$ & 49 & 72 & 95 & 119 & 39 \\
\hline P1 & 38 & 57 & 69 & 88 & 31 \\
\hline P2 & 25 & 38 & 50 & 70 & 30 \\
\hline
\end{tabular}

It can be noticed that increasing the nominal oxygen content of the alloys decreases the transformation temperatures as already observed in [2]. 


\subsection{Thermomechanical properties}

The tensile stress-strain curves at $20^{\circ} \mathrm{C}$ for fully martensitic mode (Fig.3) show that the ultimate tensile strenght is similar ( $\sim 800 \mathrm{MPa})$ for all the alloys. The critical stress corresponding to the horizontal yield plateau (due to rearrangement of the orientation of martensitic variants) increases with the As temperature (except for P1). This can be related to the mobility of the martensite-martensite interfaces which is assumed to be enhanced for temperatures close to the martensite $=>$ austenite transformation temperature range [8] [9]. Moreover, the total elongation to failure is greater for PM products (elongations of over $45 \%$ ). Ductility improvement for the PM alloys is associated with an easier orientation of martensite under stress as confirmed by reversible strain-temperature cycles with constant stress (flexion tests - Fig.5) : for the same applied stress (80MPa), the reversible strain due to the $M<--->A$ transformation is three times greater for PM products $(-3 \%)$ than for cast alloys. The better refinement of grain size for the PM products may explain this result [10].

Investigation of one way shape memory recovery for tensile test (Fig.4) show a good behaviour for both modes of elaboration with a shape recovery up to $80 \%$ for $4 \%$ strain. However, it seems that the best results are obtained for the $\mathrm{PM}$ alloy with $1200 \mathrm{ppm} \mathrm{O}_{2}$.

The stress-strain curves presented in Fig. 6 show the evolution of the recovery stress $\left(\sigma_{R}\right)$, for the PM alloy (P2), during thermomechanical cycling. A significant increase of the typical mechanical characteristics during the early stages of cycling is observed. The seventh cycle seems to correspond to the beginning of a stabilization (Fig. 8). The recovery stress increase is mainly due to the cumulative true plastic deformation $\left(\varepsilon_{\mathrm{Ri}}\right)$ which occurs on each cycle, and which induces a progressive strain hardening of the austenite. For cumulative cold working, the slip of dislocations becomes more and more difficult while the twin boundaries mobility is less affected [11]. So, the reorientation of martensite is enhanced after several thermomechanical cycles and then the residual strain $\left(\varepsilon_{\mathrm{Ri}}\right)$ is reduced and the shape recovery is improved. Moreover, the stress recovery evolution (Fig. 7) which occurs during heating after cold straining seems to be the consequence of a two-stage under-heating phase transformation : the R-phase transition $\left\{\mathrm{M}\left(\mathrm{B}^{\mathrm{B}} \mathbf{9}^{\prime}\right)\right.$-$->R\}$ and the $B 2$ transition $\{R-->A(B 2)\}$. Indeed, a change in the lattice parameter of the R-phase is induced by cold deformation [12] and under residual oriented stress, the most favourable $R$-phase variant (among the four possible types) can be formed from the remaining variants by twinning deformation. During the first cycle, the separation between the two transitions appears clearly (Fig.7), but after several cycles, the deconvolution of the two types of phase transformation becomes impossible.

By way of conclusion, the best recovery characteristics are obtained during thermomechanical cycling for the PM alloy containing 1200ppm of oxygen (P2), while the AM product with the lowest oxygen content (C3) displays a worse behaviour. One can suggest that $\mathrm{Ti}_{4} \mathrm{Ni}_{2} \mathrm{O}$ type oxides act as "preferential sites" for the nucleation of oriented variants of martensite. Further microstructural studies will be necessary to verify this assumption.

\section{REFERENCES}

[1] BARCELO F., OLIER P. \& BRACHET J.C., Rev. de Métall. CIT / Sci. et Gén. des Mat., Feb. 1994, p. 342

[2] UEHARA S., SASANO H., SUZUKI T,, Proc. TDA Ti Conf. (1982) 840

[3] ROZNER A.G., HEINTZELMAN E.F., BUEHLER W.J., GILFRICH J.V., Trans. of the ASM 58, (1965), 415

[4] MOORE J.J., YT H.C., Mater. Sci. Forum 56-58, (1990), 637-642

[5] MUELLER M.H., KNOTT H.W., Trans. of Met. Soc. of AIME 227, (1963), 674-677

[6] JACKSON C.M., WAGNER H.J., WASILEWSKI R.J., Spec. Publ. NASA-SP 5110, 1972

[7] ESCHER K., HUHNER M., Pract. Met. 27, (1990), 231-235

[8] RODRIGUEZ P., Doctoral thesis, INSA-Lyon, (1989) 185

[9] KATO H., KOYARI T., TOKIZANE M., MIURA S., Acta metal. mater. 4, (1994), 1351

[10] JANSSEN J., WILLEMS F., VERELST B., MARTENSE J., DELAEY L., J. Phys. Suppl. C4, (1982), 809

[11] LIN H.C., WU S.K., Acta metall mater. 42 N5, (1994), 1623-1630

[12] MIYAZAKI S., WAYMAN C.M., Acta metall. $36 \mathrm{~N}^{\circ} 1$, (1988), 181-192 


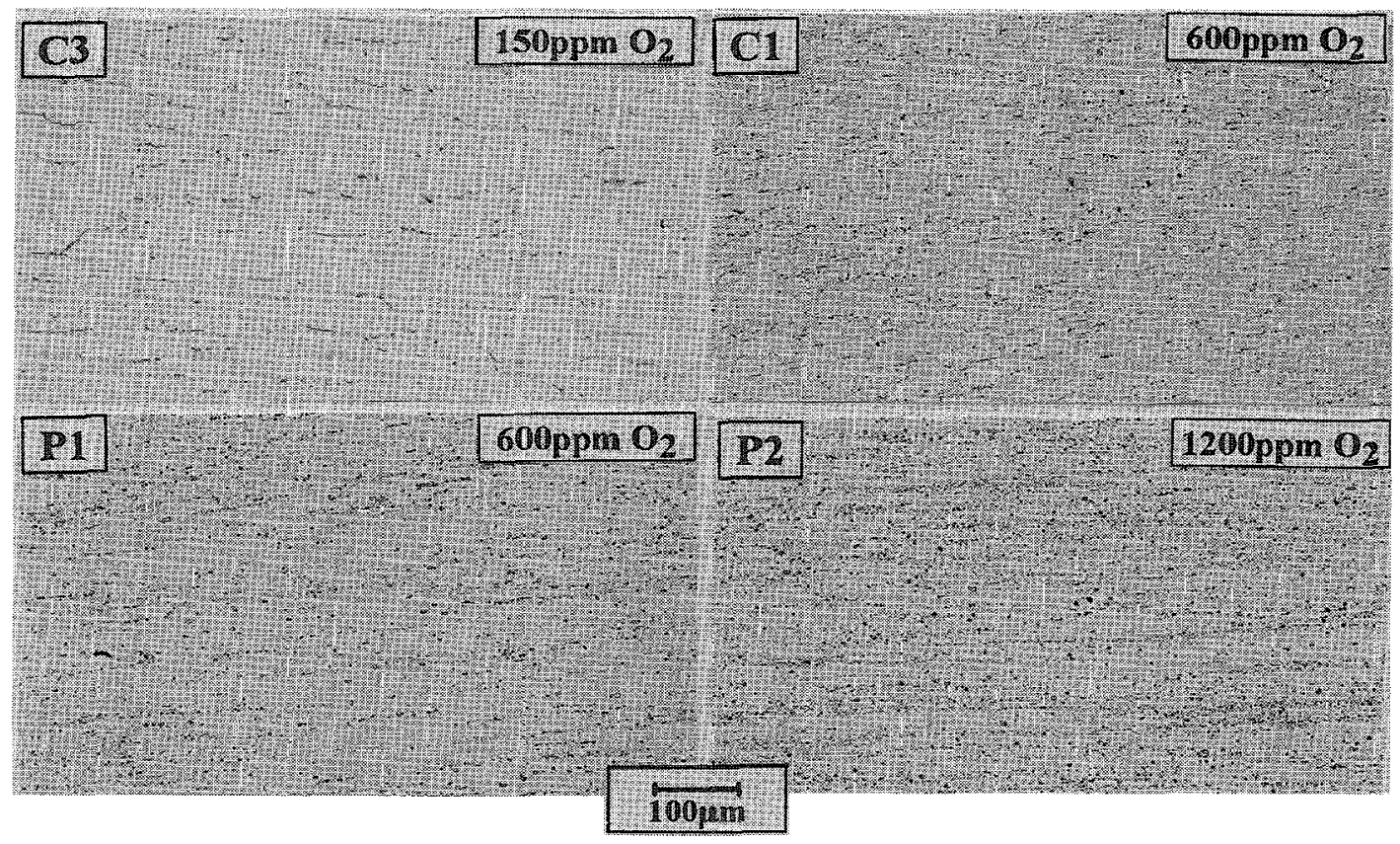

Fig. 1 : Optical micrographs (obtained after electrolytic polishing) showing the distribution of precipitates in NiTi as function of the fabrication route and of the oxygen content.
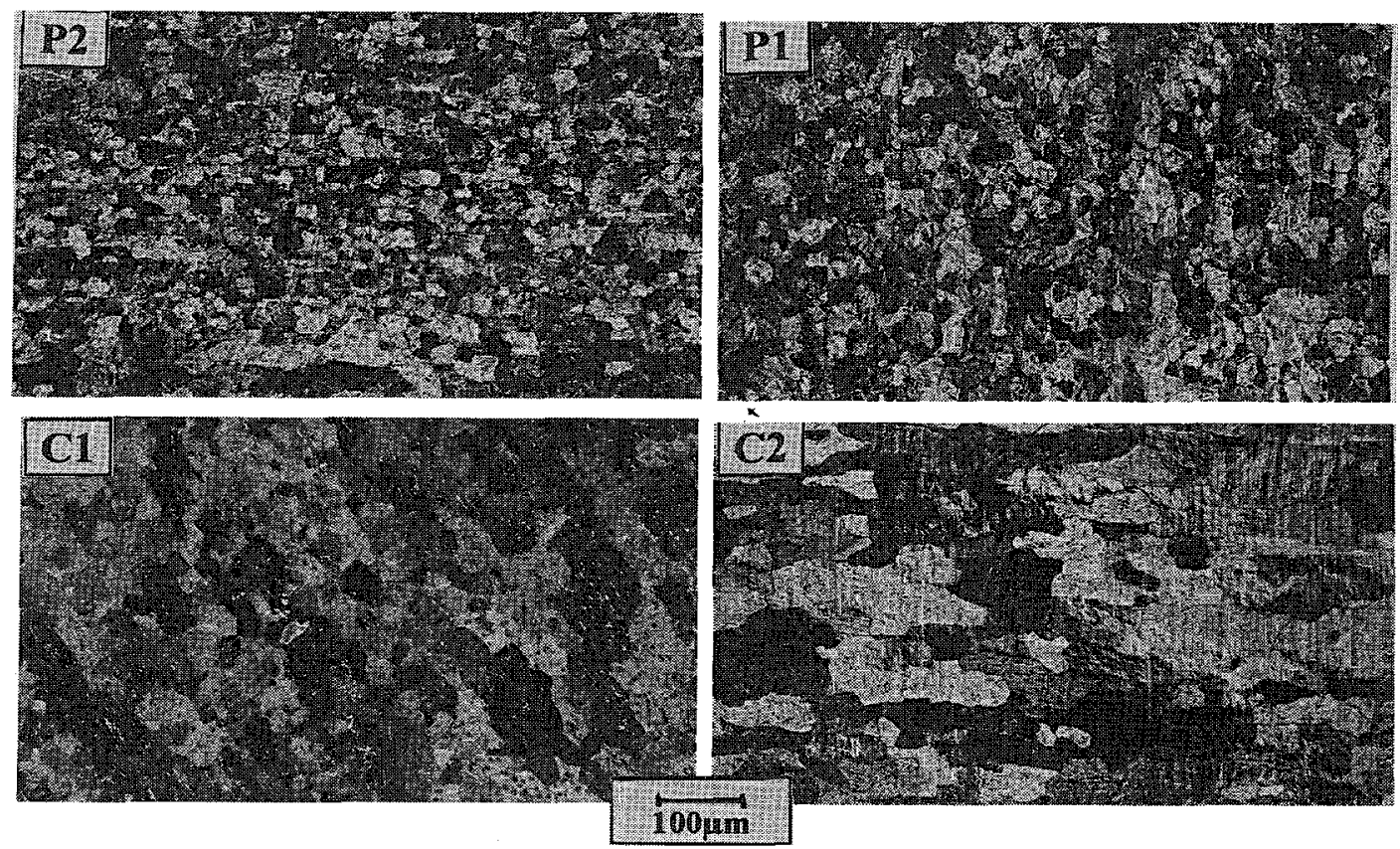

Fig. 2 : Optical micrographs (obtained after colour etching) showing the microstructure of arcmelted and PM products. 


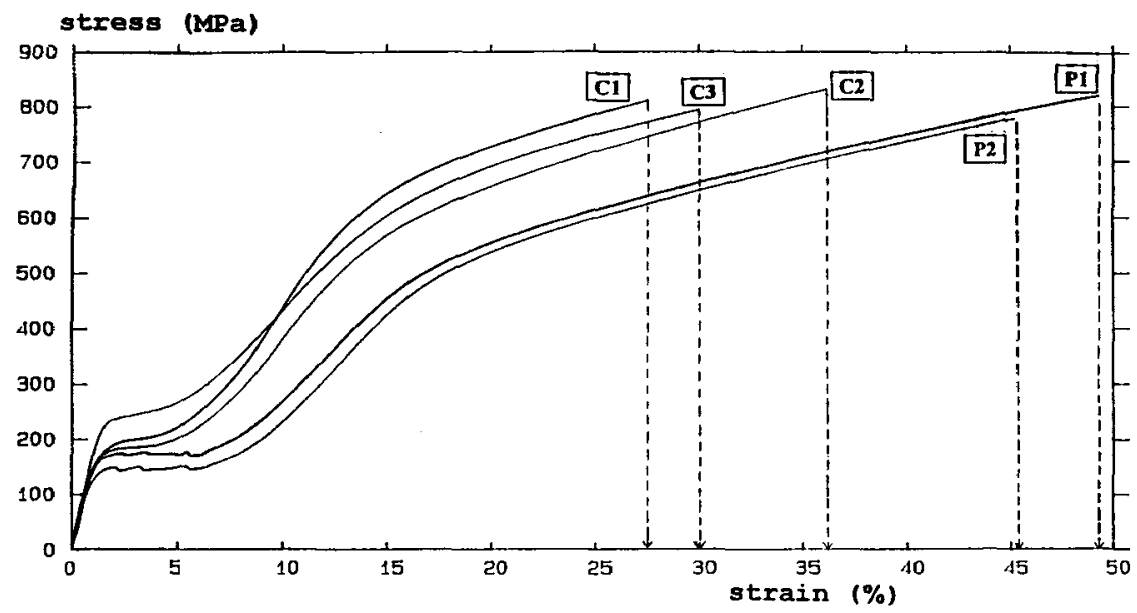

Fig. 3 : Typical stress-strain curves for tensile tests conducted to failure of $\mathrm{AM}$ products $(\mathrm{C} 1, \mathrm{C} 2, \mathrm{C} 3)$ and $\mathrm{P} \mathbf{M}$ products (P1,P2). Tensile tests were carried out at $20^{\circ} \mathrm{C}$ in fully martensitic mode.

Shape memory recovery $(\%)$

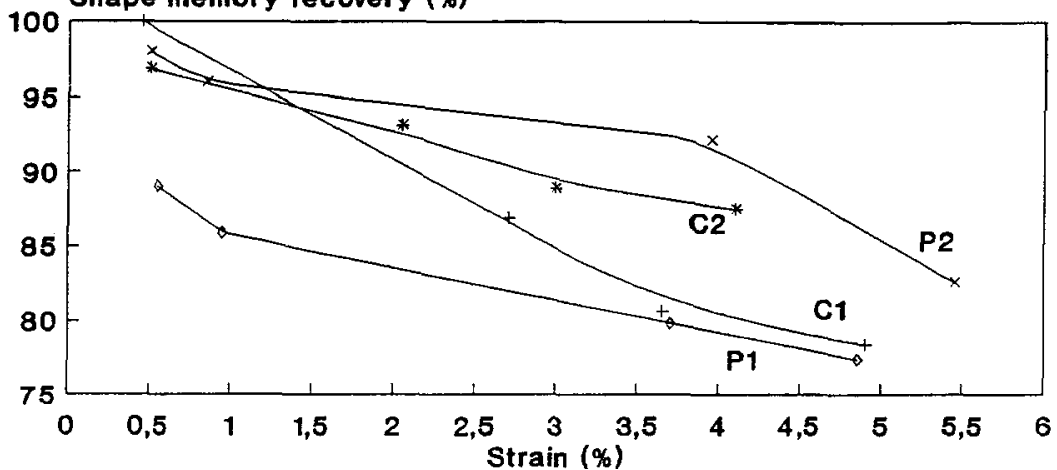

Fig. 4: Evolution of the one way shape memory effect as function of the applied tensile strain in martensitic mode.

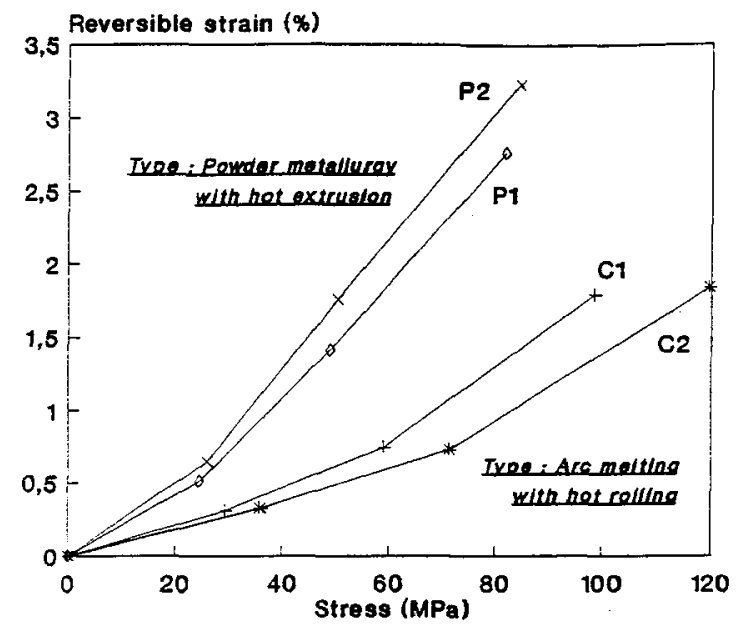

Fig. 5 : Relation between the applied stress in austenitic mode and the reversible strain due to

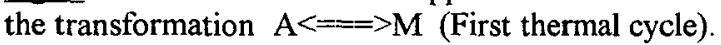




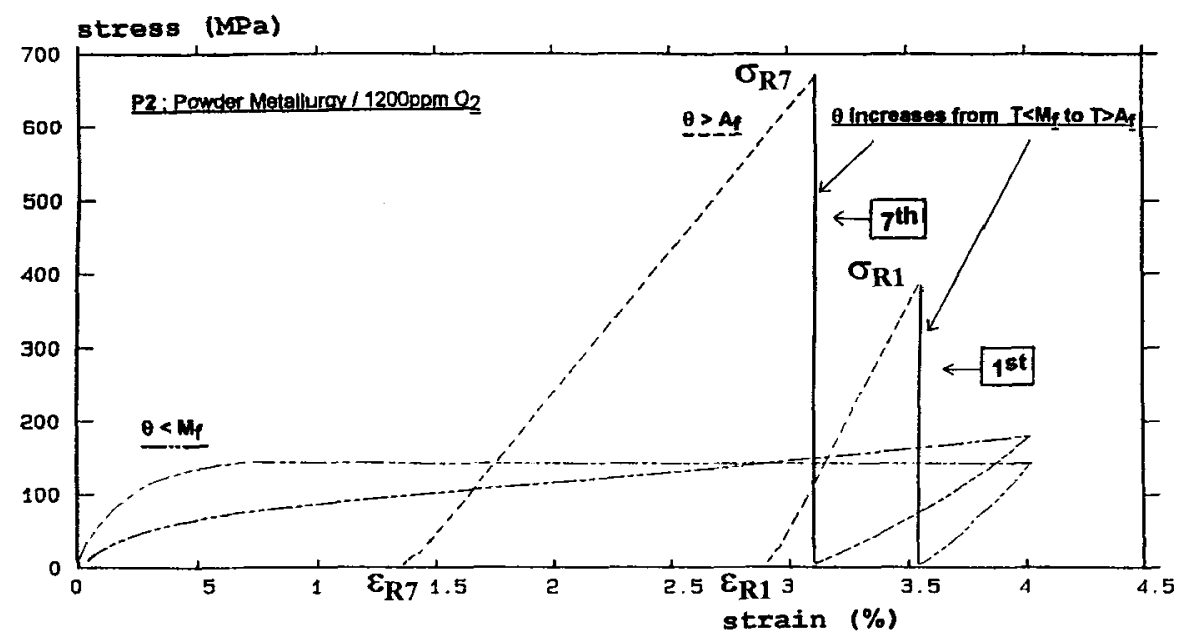

Fig. 6: Typical evolution of stress-strain characteristics after seven specific tensile tests.

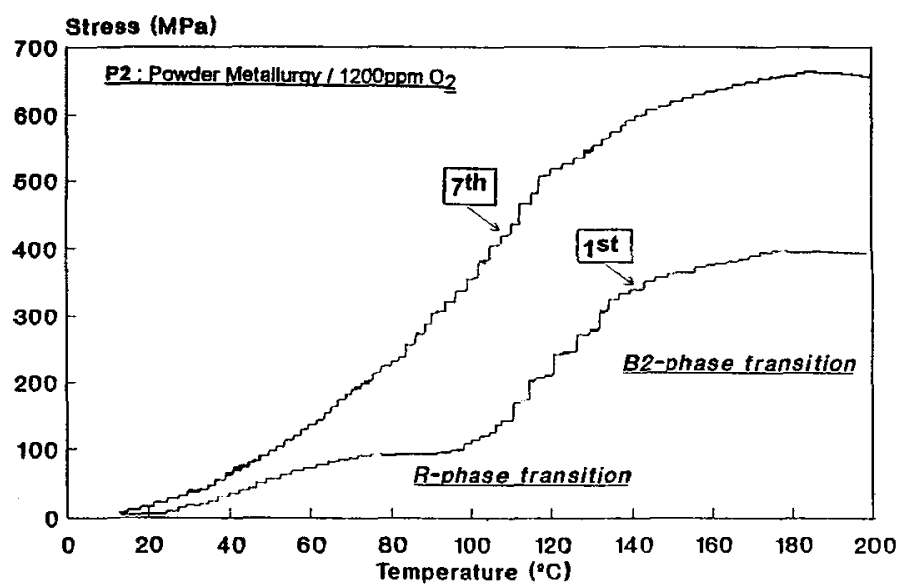

Fig. 7: Evolution of the recovery stress during the heating at $5^{\circ} \mathrm{C} / \mathrm{min}$, from $\theta=20^{\circ} \mathrm{C}$ up to $\theta>A_{\mathrm{f}}$ (with a constant strain).

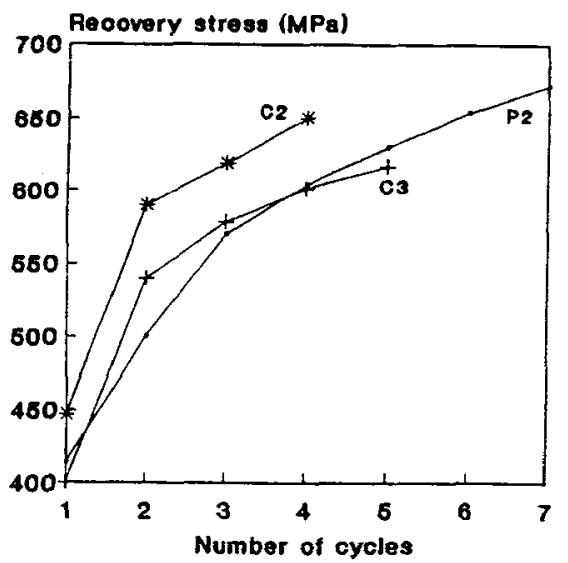

Fig. 8 : Dependence of recovery stress on the number of heating cycles. 